\title{
Predissection-derived geometric and distensibility indices reveal increased peak longitudinal stress and stiffness in patients sustaining acute type $A$ aortic dissection: Implications for predicting dissection
}

Leonid Emerel, MD, ${ }^{\mathrm{a}}$ James Thunes, PhD, ${ }^{\mathrm{b}}$ Trevor Kickliter, BS, ${ }^{\mathrm{b}}$ Marie Billaud, PhD, ${ }^{\mathrm{a}, \mathrm{b}, \mathrm{c}}$ Julie A. Phillippi, PhD, ${ }^{\mathrm{a}, \mathrm{b}, \mathrm{c}, \mathrm{d}}$ David A. Vorp, $\mathrm{PhD},{ }^{\mathrm{a}, \mathrm{b}, \mathrm{c}, \mathrm{d}, \mathrm{e}}$ Spandan Maiti, $\mathrm{PhD},{ }^{\mathrm{b}}$ and Thomas G. Gleason, MD ${ }^{\mathrm{a}, \mathrm{b}, \mathrm{c}, \mathrm{d}, \mathrm{f}}$

\section{ABSTRACT}

Objective: To assess ascending aortic distensibility and build geometry and distensibility-based patient-specific stress distribution maps in patients sustaining type A aortic dissection (TAAD) using predissection noninvasive imaging.

Methods: Review of charts from patients undergoing surgical repair of TAAD $(\mathrm{n}=351)$ led to the selection of a subset population $(\mathrm{n}=7)$ with 2 or more predissection computed tomography angiography scans and echocardiograms at least 1 year before dissection. Ascending aortic wall biomechanical properties (aortic strain, distensibility, and stiffness) were compared with age- and size-matched nondissected nonaneurysmal controls. Patient-specific aortic strain served as an input in aortic geometry-based simulated 3-dimensional reconstructions to generate longitudinal and circumferential wall stress maps. Inspection of perioperative dissection scans and intraoperative visual examination confirmed primary tear locations.

Results: Predissection echocardiography revealed ascending aortas of patients sustaining TAAD to exhibit decreased aortic wall strain $(14.50 \pm 1.13 \%$ vs $8.49 \pm 1.08 \% ; P<.01)$, decreased distensibility $(4.26 \pm 0.44$ vs $2.39 \pm 0.33$ $10^{-6} \mathrm{~cm}^{2} \cdot$ dyne $\left.{ }^{-1} ; P<.01\right)$, increased stiffness $(3.84 \pm 0.24$ vs $7.48 \pm 1.05$; $P<.001)$, and increased longitudinal wall stress $(246 \pm 22$ vs $172 \pm 37 \mathrm{kPa}$; $P<.01)$. There was no significant difference in circumferential wall stress. Predissection computed tomography angiography models revealed overlap between regions of increased longitudinal wall stress and primary tear sites.

Conclusions: Using predissection imaging, we identified increased stiffness and longitudinal wall stress in ascending aortas of patients with dissection. Patientspecific imaging-derived biomechanical property maps like these may be instrumental toward designing better prediction models of aortic dissection potential. ( $\mathrm{J}$ Thorac Cardiovasc Surg 2019;158:355-63)

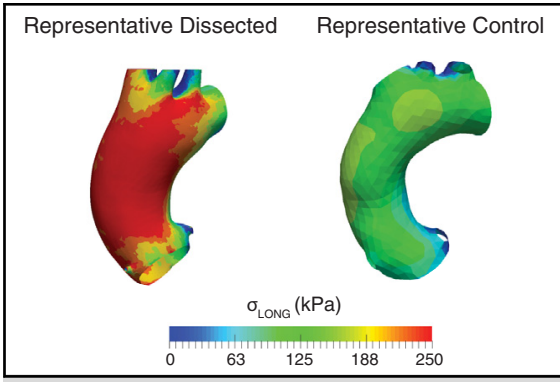

Longitudinal but not circumferential wall stress is elevated in patients sustaining dissection.

\section{Central Message}

Patient-specific ascending aortic wall biomechanical and geometric properties generate wall stress models toward predicting aortic dissection potential.

\section{Perspective}

Little is known about which aortic wall biomechanical abnormalities may predispose to type A aortic dissection. Multiparameter biomechanical wall stress prediction models could help identify how these properties influence dissection potential and may offer a distinct opportunity for improved risk stratification and management of aortic disease.

See Commentaries on pages 364 and 366.

\footnotetext{
From the ${ }^{\mathrm{a}}$ Department of Cardiothoracic Surgery, ${ }^{\mathrm{b}}$ Department of Bioengineering, ${ }^{\mathrm{c}}$ McGowan Institute for Regenerative Medicine, ${ }^{\mathrm{d}}$ Center for Vascular Remodeling and Regeneration, ${ }^{\mathrm{e}}$ Department of Chemical \& Petroleum Engineering, and ${ }^{\mathrm{f}} \mathrm{Cen}-$ ter for Thoracic Aortic Disease, University of Pittsburgh, Pittsburgh, Pa.

Research reported in this publication was supported by the National Heart, Lung, and Blood Institute of the National Institutes of Health under award \#HL109132 (to T.G.G.).

Read at the 98th Annual Meeting of The American Association for Thoracic Surgery, San Diego, California, April 28-May 1, 2018.

Drs Emerel and Thunes contributed equally to this article.
}

Received for publication April 16, 2018; revisions received Oct 17, 2018; accepted for publication Oct 26, 2018; available ahead of print Dec 11, 2018.

Address for reprints: Thomas G. Gleason, MD, Ronald V. Pellegrini Endowed Professor of Cardiothoracic Surgery Chief, Division of Cardiac Surgery, University of Pittsburgh School of Medicine Co-Director, UPMC Heart and Vascular Institute Director, UPMC Center for Thoracic Aortic Disease, Shadyside Medical Building, 5200 Centre Ave, Suite 715, Pittsburgh, PA 15232 (E-mail: gleasontg@upmc.edu). $0022-5223 / \$ 36.00$

Copyright (c) 2018 by The American Association for Thoracic Surgery

https://doi.org/10.1016/j.jtcvs.2018.10.116 


\section{Abbreviations and Acronyms \\ $\mathrm{AoD}=$ ascending aortic diameter at end diastole \\ AoS = ascending aortic diameter at peak systole \\ $\mathrm{BAV}=$ bicuspid aortic valve \\ CTA = computed tomography angiography \\ DBP $=$ diastolic blood pressure \\ $\mathrm{SBP}=$ systolic blood pressure \\ $\mathrm{TAAD}=$ type $\mathrm{A}$ aortic dissection}

morphology. ${ }^{12-14}$ However, limitations that restrict the accuracy and validity of these models included both a lack of patient-specific in vivo aortic wall biomechanical parameters as model inputs and the clinical knowledge of whether a dissection actually ever occurred. We hypothesized that patients sustaining TAAD exhibit abnormal aortic wall biomechanical properties before the development of dissection, which can be used to generate a computational model and predict wall stress measurements. We focused on the interrogation of patient-specific imaging parameters (aortic geometry and distensibility) from patient's images generated well before they dissected.

\section{METHODS}

\section{Cohort Selection}

All patients undergoing surgical repair of acute TAAD within a single institution were prospectively included in a database and reviewed between 2007 and $2016(\mathrm{n}=351)$. All patients identified gave informed consent for chart evaluation and study (institutional review board \#PRO07020120). Inclusion criteria for this study included the presence of a computed tomography angiography (CTA) scan at the time of dissection diagnosis (perioperative CTA), 2 or more CTAs obtained at least 1 year before dissection (predissection CTA), and at least 1 predissection transthoracic echocardiogram. Exclusion criteria included incidence of acute TAAD within 1 year of a surgical procedure requiring manipulation of the ascending aorta (coronary bypass grafting with proximal aortic anastomosis, aortic valve replacement, or placement of a ventricular assist device) or TAADs caused by retrograde propagation after thoracic aortic endovascular stenting to derive the final cohort $(n=7)$. Control patients $(n=7)$ studied were non-BAV, with no known connective tissue disorder and no previous history of ascending aortic aneurysm, who were matched to the experimental cohort for age and body size (body mass index and body surface area). Control patients were outpatient referrals seen for evaluation for other conditions who did not undergo surgery. However, it is our policy to also obtain consent from these patients for clinical research purposes.

\section{Identification of Intimal Tear Location}

All CTAs at the time of dissection and detailed operative notes from the surgical repairs were reviewed by the senior aortic surgeon (T.G.G.) to identify the primary intimal tear location. Stress maps were derived from computational models by engineers (J.T. and S.M.) who were blinded to tear site locations. Tear site locations were compared with stress maps only after completion of all stress maps.

\section{Calculation of Aortic Strain, Distensibility, and Stiffness}

Aortic elasticity was assessed using the parasternal long axis window of 2-dimensional transthoracic echocardiography. Ascending aortic diameter at peak systole (AoS) and ascending aortic diameter at end diastole (AoD) measurements were made $3 \mathrm{~cm}$ above the aortic valve annulus; $\mathrm{AoD}$ was obtained at the peak of the $\mathrm{R}$ wave in the simultaneously recorded electrocardiogram, whereas AoS was measured at the initiation of the $\mathrm{T}$ wave. The following indices of aortic elasticity were calculated as previously described ${ }^{9,15,16}$ :

$$
\begin{gathered}
\text { Cardiac cycle aortic wall strain }(\%)=100 \frac{A o s-A o D}{A o D} \\
\text { Distensibility }\left(10^{-6} \mathrm{~cm}^{2} \cdot \text { dyne }^{-1}\right)=2 \frac{\mathrm{AoS}-\mathrm{AoD}}{A o D \times P P} \\
\text { Stiffness Index }=\frac{\ln (\mathrm{SBP} / \mathrm{DBP})}{A o S-A o D} \mathrm{AoD}
\end{gathered}
$$


Pulse pressure was calculated as systolic blood pressure (SBP) - diastolic blood pressure (DBP), and $\ln (\mathrm{SBP} / \mathrm{DBP}$ ) refers to the natural logarithm of the relative pressure. Blood pressure was measured at the time of echocardiography using a cuff sphygmomanometer. Phase 1 and Phase 5 Korotkoff sounds were used for SBP and DBP, respectively. All measurements were made by a single observer with 3 to 5 measurements per patient, all before the calculation of stain, distensibility, and stiffness indices.

\section{Reconstruction of Axial CTA Cuts into 3-Dimentional Images}

Aortic geometry was extracted from CTAs using Mimics (Materialize, Leuven, Belgium). Model geometry began near the aortic valve annulus and continued approximately 10 to $15 \mathrm{~cm}$ distal to the aortic arch. Any artifacts in the resulting surface model were removed in Geomagic (3D Systems, Rock Hill, SC). The subsequent blank reconstructions were created in duplicates for each patient and one given to the senior aortic surgeon for primary tear location mapping and one to the engineering team for stress map generation in a blind fashion. The blank engineering model was then meshed with 3-noded triangular elements in Trelis (csimsoft, American Fork, Utah). The resulting finite element meshes for the aortic models contained 30,000 to 50,000 elements to be used for computational model formation (Figure 1).

\section{Patient-Specific Estimation of Aortic Wall Material Parameters}

A 2-parameter isotropic constitutive model, previously developed by members of our group for abdominal aortic tissue, ${ }^{17}$ was used to simulate biomechanical behavior of the thoracic aortic wall tissue. This model was chosen as a minimally complex constitutive relation capable of capturing the behavior of the tissue. Instead of other popular relations in the literature, ${ }^{18}$ this model does not include collagen or elastin fiber directions-data impractical for noninvasive clinical measurement. The strain energy density function for the model is given by the following:

$$
\Psi=\alpha\left(I_{1}-3\right)+\beta\left(I_{1}-3\right)^{2}
$$

where $I_{1}=\operatorname{trC}$ is the first invariant of the right Cauchy-Green deformation tensor, $\mathrm{C}$, and $\alpha$ and $\beta$ are material parameters. These material parameters were determined in a patient-specific basis by fitting simulated aortic strain to the aortic strain data collected by predissection echocardiography. Individual patient geometries were pressurized to the blood pressure at the time
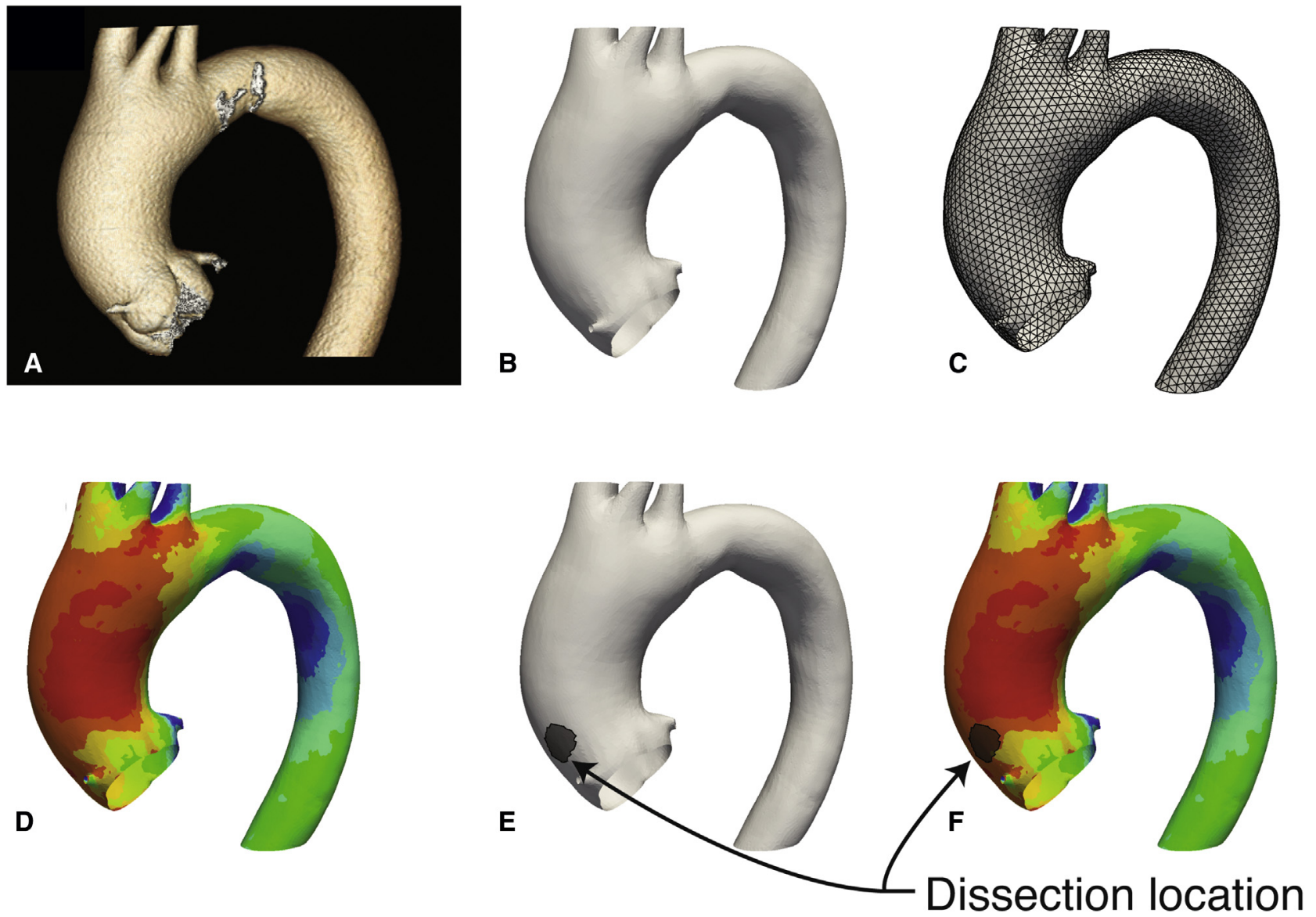

FIGURE 1. Representative imaging reconstruction and biomechanical stress analysis process. Patient predissection computed tomography angiography scans (A) were reconstructed into 3-dimensional surfaces based on ascending aortic geometry (B), and then discretized for finite element analysis (C). Finite element simulations were performed to obtain longitudinal biomechanical stress contour maps on the aortic wall (D). Clinically observed dissection origins (E) were plotted on the aortic models and were subsequently contrasted against stress contours (F). 
TABLE 1. Baseline characteristics

\begin{tabular}{|c|c|c|c|}
\hline & $\begin{array}{l}\text { Dissected } \\
\text { cohort } \\
(n=7)\end{array}$ & $\begin{array}{c}\text { Nondissected } \\
\text { controls } \\
(n=7)\end{array}$ & $\begin{array}{c}P \text { value } \\
\text { dissected } \\
\text { vs controls }\end{array}$ \\
\hline Age, y & $62.25 \pm 3.46$ & $61.71 \pm 3.52$ & ns \\
\hline Sex, $\%$ males & 71 & 71 & ns \\
\hline Height, cm & $175.73 \pm 2.98$ & $172.43 \pm 3.33$ & ns \\
\hline Weight, kg & $88.61 \pm 6.78$ & $88.78 \pm 9.17$ & ns \\
\hline Body mass index, $\mathrm{kg} / \mathrm{m}^{2}$ & $28.69 \pm 2.10$ & $30.98 \pm 2.72$ & $\mathrm{~ns}$ \\
\hline Body surface area, $\mathrm{m}^{2}$ & $2.04 \pm 0.08$ & $2.05 \pm 0.10$ & ns \\
\hline $\begin{array}{l}\text { Maximum orthogonal } \\
\text { diameter, mm }\end{array}$ & $47.78 \pm 2.75$ & $32.14 \pm 1.64$ & $<.01$ \\
\hline \multicolumn{4}{|l|}{ Blood pressure, $\mathrm{mm} \mathrm{Hg}$} \\
\hline $\begin{array}{l}\text { SBP } \\
\text { DBP } \\
\text { PP }\end{array}$ & $\begin{array}{r}128.77 \pm 7.01 \\
72.78 \pm 5.32 \\
56.00 \pm 5.50\end{array}$ & $\begin{aligned} 126.88 & \pm 6.35 \\
71.71 & \pm 4.54 \\
53.75 & \pm 5.14\end{aligned}$ & $\begin{array}{l}\text { ns } \\
\text { ns } \\
\text { ns }\end{array}$ \\
\hline $\mathrm{AoS}, \mathrm{cm}$ & $4.39 \pm 0.23$ & $3.61 \pm 0.22$ & $<.05$ \\
\hline AoD, $\mathrm{cm}$ & $4.06 \pm 0.22$ & $3.15 \pm 0.18$ & $<.05$ \\
\hline $\mathrm{AoS}-\mathrm{AoD}, \mathrm{cm}$ & $0.33 \pm 0.03$ & $0.46 \pm 0.06$ & $<.05$ \\
\hline $\begin{array}{l}\text { Cardiac cycle aortic } \\
\text { wall strain, } \%\end{array}$ & $8.49 \pm 1.08$ & $14.50 \pm 1.13$ & $<.01$ \\
\hline $\begin{array}{l}\text { Distensibility, } \\
\qquad 10^{-6} \mathrm{~cm}^{2} \cdot \mathrm{dyne}^{-1}\end{array}$ & $2.39 \pm 0.33$ & $4.26 \pm 0.44$ & $<.01$ \\
\hline Stiffness index & $7.48 \pm 1.05$ & $3.84 \pm 0.24$ & $<.001$ \\
\hline
\end{tabular}

Data are expressed as means \pm standard error of the mean unless otherwise specified $P$ values calculated by the Mann-Whitney $U$ test. $n s$, Not statistically significant; $S B P$, systolic blood pressure; $D B P$, diastolic blood pressure; $P P$, pulse pressure; $A o S$, ascending aortic diameter at peak systole; $A o D$, ascending aortic diameter at end diastole.

of echocardiography to obtain the simulated aortic strain measured $3 \mathrm{~cm}$ above the aortic root. Material parameters $(\alpha$ and $\beta$ ) were modified until the absolute difference between the computationally calculated and clinically measured aortic strain values were $<5 \%$ from one another. To reduce the potential that a local minima was obtained from the fitting process, 10 initial guesses were used for the parameters. Multiple runs confirmed the uniqueness of the 2 parameters we used.

\section{Finite Element Simulation and Generation of Wall Stress Maps}

Wall stress analysis was performed using a custom nonlinear membrane finite element software package previously developed by the members of our group. ${ }^{19}$ The models were constrained against movement at the boundaries of the domain and a pressure of $200 \mathrm{~mm} \mathrm{Hg}$ was applied to the luminal surface of the aorta. Finite element simulations yielded the patient-specific distributions of $\sigma_{L O N G}$ and $\sigma_{C I R C}$, the longitudinal and circumferential stresses in the aortic wall tissue, respectively. These stress components were postprocessed using Paraview (Kitware, Clifton Park, NY) for visualization purposes. Only the region of interest (ascending aorta) was visually displayed for this paper's objective.

\section{Statistical Methods}

All results mentioned in the text are expressed as mean \pm standard error of the mean. Data in Table 1 are expressed as median \pm standard error of
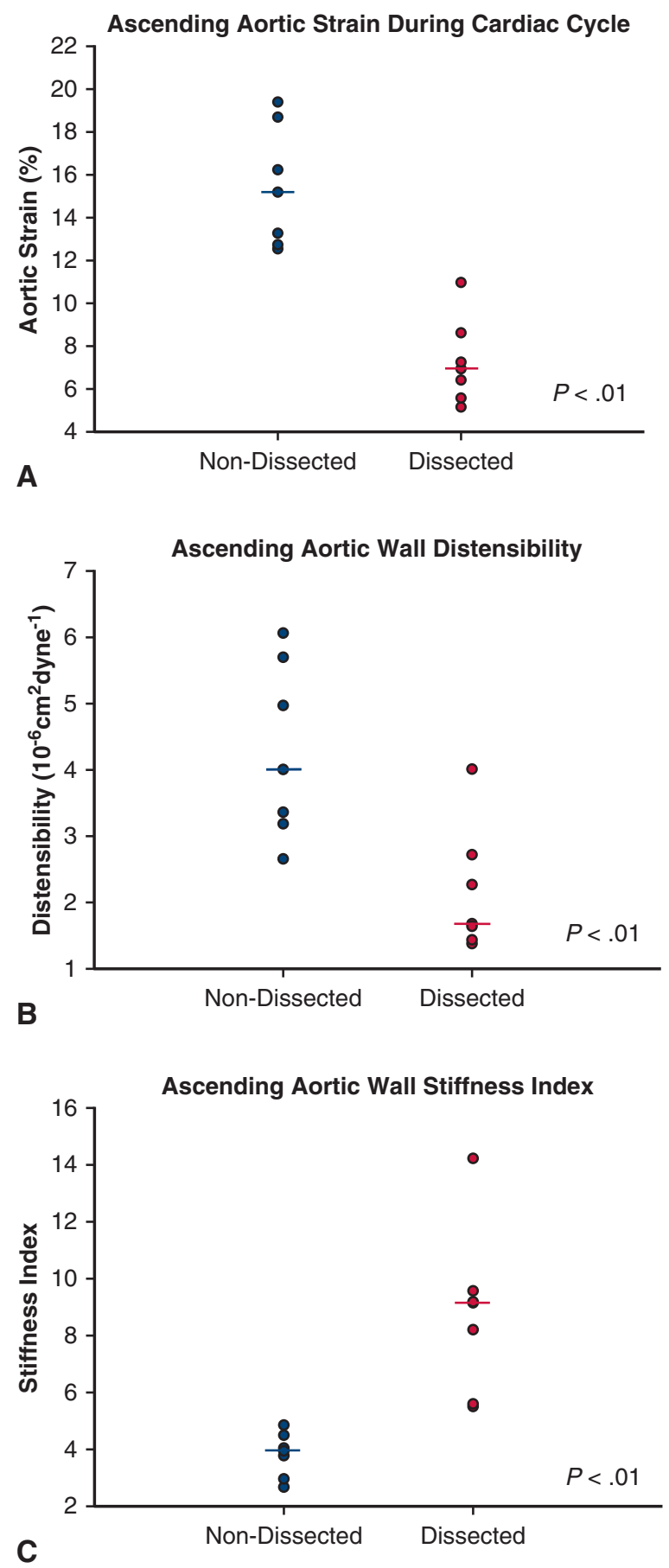

FIGURE 2. Predissection echocardiography demonstrates aberrant aortic wall biomechanics in patients sustaining type A aortic dissection. Cardiac cycle aortic strain, distensibility, and stiffness were quantified using transthoracic echocardiography. Dissection patients were found to have decreased aortic wall strain (A) and distensibility (B) and elevated stiffness (C). Dot plots indicate individual measurements, with horizontal bars serving as the median value.

the mean. Data in Figures 2 and 5 are expressed as individual values. Statistical tests were performed using SigmaPlot, version 12.5 (SYSTAT Software, San Jose, Calif). Comparisons between group demographics were 


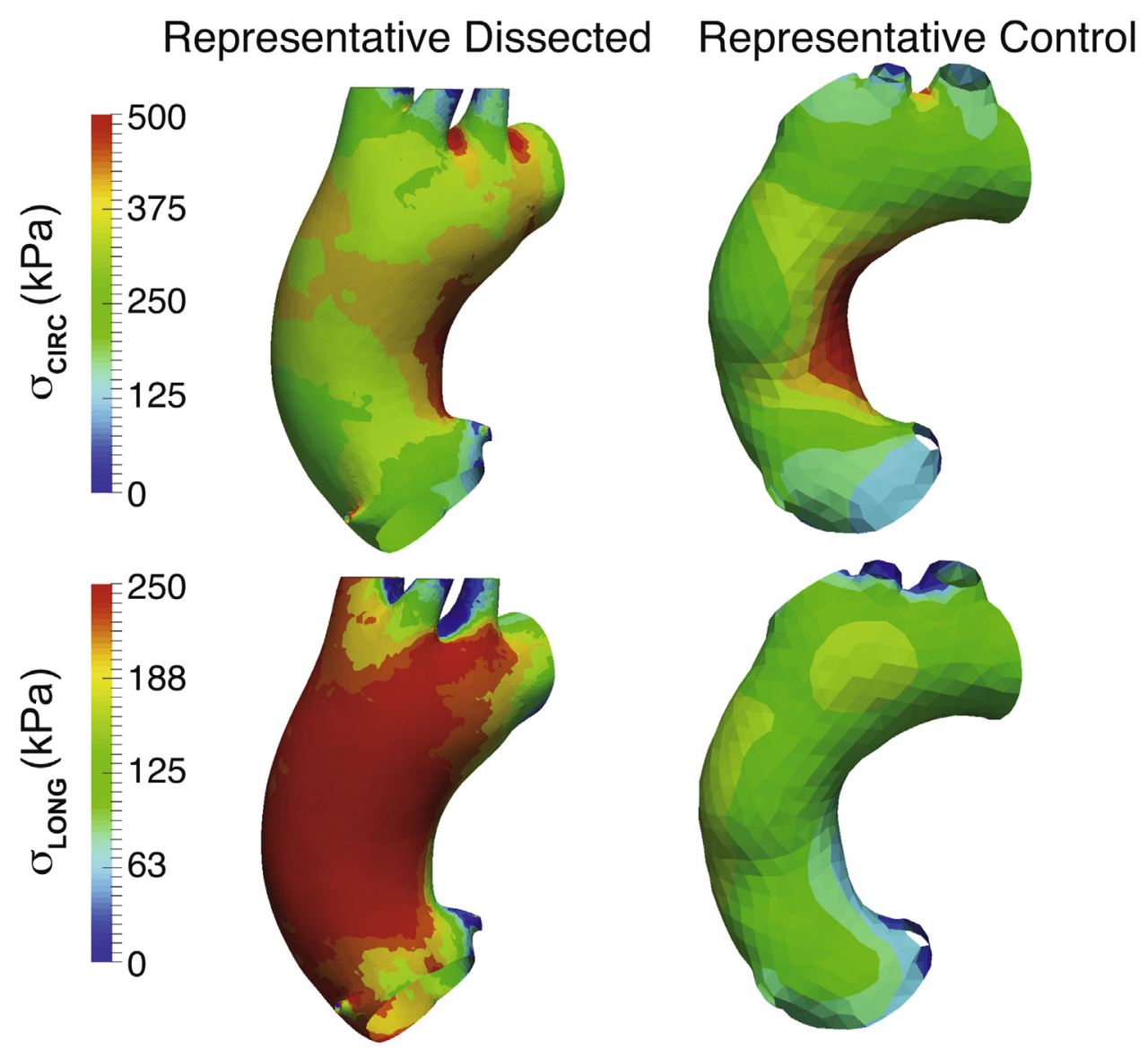

FIGURE 3. Representative models to demonstrate longitudinal stress is elevated in patients sustaining type A dissection versus nondissected matched controls. Finite element analyses for representative dissected patients and control aortas after pressurization to $200 \mathrm{~mm} \mathrm{Hg}$. The top row shows the stress contours in the circumferential direction and the bottom row the stress contours in the longitudinal directions. Magnitudes of circumferential stress is similar between the aortic models whereas longitudinal stress is significantly greater in the representative dissected aortic model.

assessed by the Mann-Whitney U test. $P<.05$ was considered statistically significant.

\section{RESULTS}

\section{Patient Characteristics}

Baseline patient characteristics of both the TAAD and control cohorts are summarized in Table 1. Mean age of the TAAD patient subset was $62.3 \pm 3.5$ years, with a $5: 2$ male/female ratio. Mean age of the control patient subset was $61.7 \pm 3.5$ years, with a 5:2 male/female ratio. All patients in both the TAAD and control cohorts had a morphologically normal tricuspid aortic valve and no history of connective tissue disorders. There were no differences between the 2 cohorts in age, sex distribution, height, weight, body mass index, body surface area, SBP, DBP, or pulse pressure. Maximum orthogonal diameters were larger among study patients compared with controls $(47.8 \pm 2.75 \mathrm{~mm}$ vs $32.1 \pm 1.64 \mathrm{~mm} ; P<.01)$. Six of seven $(86 \%)$ patients in the TAAD cohort exhibited a maximum ascending aortic orthogonal diameter $<5.5 \mathrm{~cm}$.
Patients Sustaining Acute TAAD Exhibited Abnormal Ascending Aortic Wall Biomechanical Properties Before Dissection

Predissection aortic systolic diameters, AoS $(4.39 \pm 0.23 \mathrm{~cm}$ vs $3.61 \pm 0.22 \mathrm{~cm} ; P<.05)$, and aortic diastolic diameters, AoD $(4.06 \pm 0.22 \mathrm{~cm}$ vs $3.15 \pm 0.18 \mathrm{~cm}$ : $P<.05$ ), were increased in study patients compared with control patients. In addition, aortic wall strain during the cardiac cycle $(8.49 \pm 1.08 \%$ vs $14.50 \pm 1.13 \% ; P<.01)$ and distensibility $\left(2.39 \pm 0.33\right.$ vs $4.26 \pm 0.4410^{-6} \mathrm{~cm}^{2} \cdot$ dyne $^{-1}$; $P<.01)$ were lower when compared with control patients, whereas aortic stiffness indices $(7.48 \pm 1.05$ vs $3.84 \pm 0.24 ; P<.001$ ) were significantly increased (Figure 2 ).

\section{Locations of Peak Longitudinal Wall Stress Overlapped with Clinically Observed Locations of Dissection Initiation}

Circumferential and longitudinal wall stress maps were generated for representative finite element aorta 

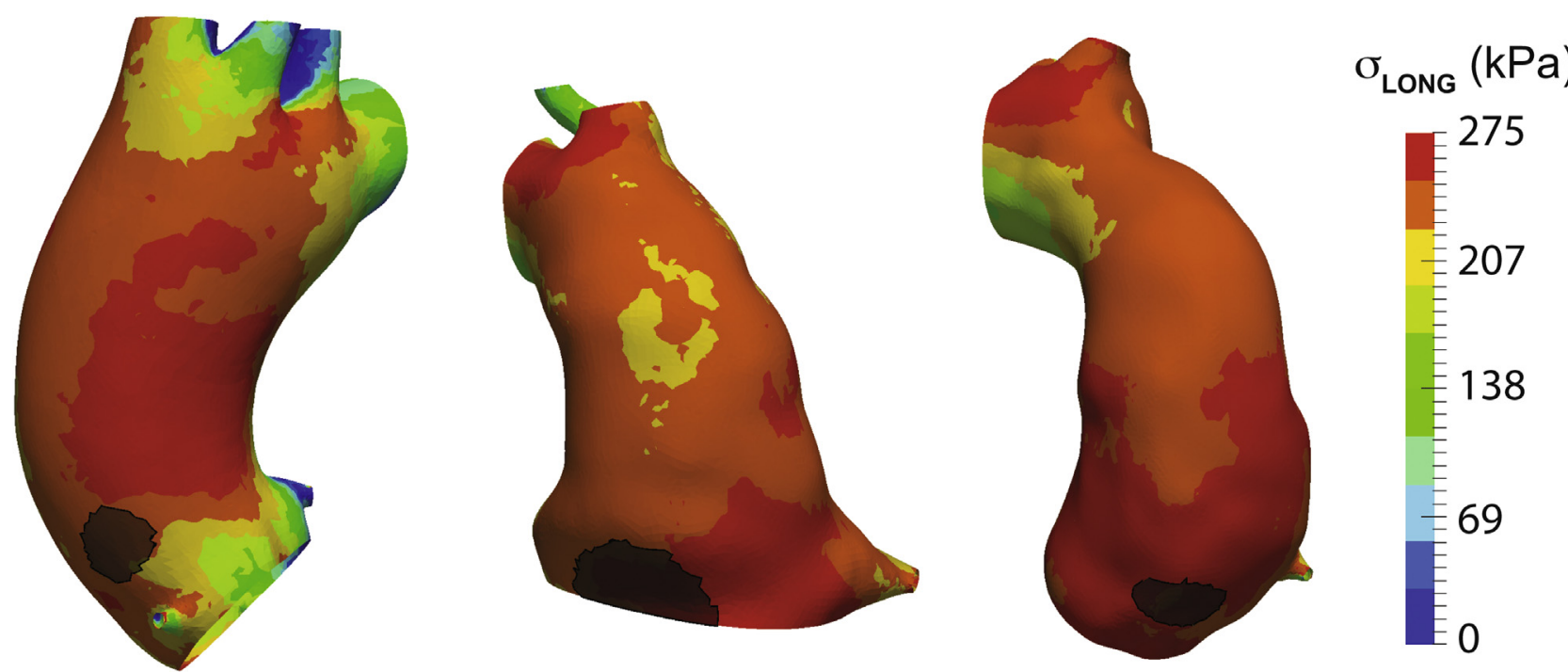

FIGURE 4. Representative finalized computational models with actual dissection origin overlay. Ascending aortic longitudinal stress maps of predissection computed tomography angiography scans with the discerned location of dissection as determined by perioperative computed tomography angiography overlaid in black.

pressurization simulations using aortic strain and geometry (Figure 3). Peak circumferential stress was located on the inner curvature, whereas peak longitudinal stress was located on the greater curvature of the ascending aorta for the aorta geometries studied. Longitudinal stress maps with surgeon-identified primary tear locations (representative patients shown in Figure 4, overlayed gray regions) were compared to the 95th percentile peak longitudinal wall stress. The peak longitudinal stress in the region of primary tear location was within $10 \%$ of calculated peak longitudinal stress in the ascending thoracic aorta on predissection models for all patients studied.

\section{Finite Element Simulations Predicted Increased Peak Longitudinal Wall Stress for the TAAD Cohort}

Peak longitudinal wall stress for the TAAD cohort was found to be greater than in control patients $(246 \pm 22 \mathrm{kPa}$ vs $172 \pm 37 \mathrm{kPa} ; P<.01)$. There was no significant difference in the peak circumferential wall stress between patients with TAAD and controls (Figure 5).

\section{DISCUSSION}

We report the use of predissection echocardiography and CTA to quantify aortic wall biomechanical properties and generate patient-specific predissection stress computational models of the ascending aorta of patients known to later sustain acute TAAD. Our findings reveal that ascending aortas of TAAD patients have decreased strain and distensibility up to more than 1 year before dissection. Computational stress maps incorporating aortic geometry and echocardiographically derived aortic distensibility demonstrate that the longitudinal peak aortic wall stress, not the circumferential, is elevated before dissection in the TAAD cohort. In addition, we found overlap between regions of elevated longitudinal wall stress and the location of primary tears.

These findings corroborate previous investigations that identified aberrant imaging-based aortic wall biomechanics in patient populations with known increased dissection risk such bicuspid aortic valve and Marfan syndrome. , $^{7,16}$ Others have previously used echocardiography to identify decreased aortic strain and increased stiffness in nonaneurysmal ascending aortas of patients with BAV when compared with age- and size-matched controls. ${ }^{9,20,21}$ After adjustment for aortic size and blood pressure, they showed that increased stiffness index positively correlated with aortic diameter. ${ }^{9}$ Nollen and colleagues ${ }^{8}$ prospectively determined aortic stiffness and diameter using magnetic resonance imaging of 78 patients with the Marfan syndrome. They found that decreased ascending aortic distensibility was a major predictor of aortic root dilatation, leading them to conclude that aortic stiffness should be assessed along with standard diameter measurements and growth rate for risk assessment and monitoring of patients with Marfan syndrome. Vitarelli and colleagues ${ }^{22}$ showed that decreased aortic wall motion and increased stiffness index were independent predictors of aortic dissection among a cohort of 31 patients with Marfan syndrome. Xuan and colleagues $^{23}$ recently reported that both longitudinal and circumferential components of the wall stress were greater in the ascending aneurysmal aorta of patients with BAV compared with patients with TAV, and peak stresses were observed at the sinotubular junction. Collectively, these reports suggest that a derangement in aortic wall load-bearing 

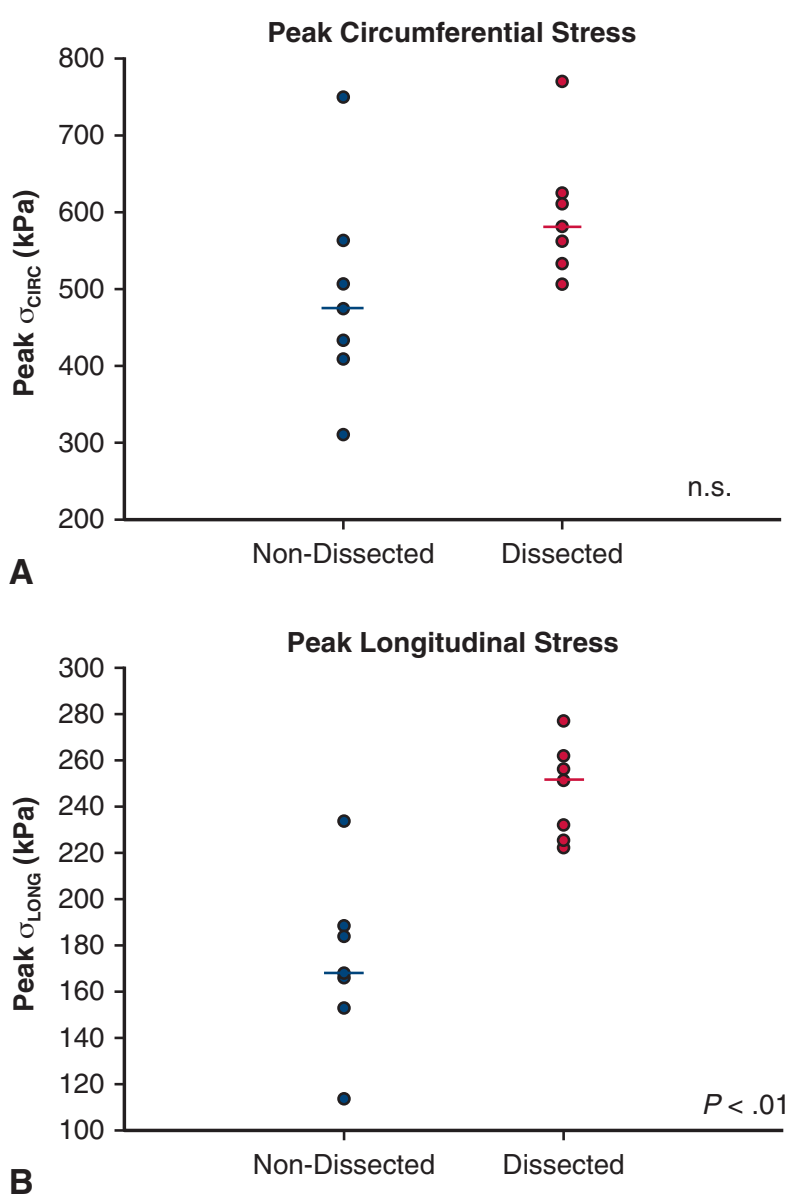

FIGURE 5. Peak longitudinal stress is elevated in patients sustaining type A aortic dissection. Peak longitudinal stress was quantified using finite element simulation of the computational models. Dissection patients were found to have increased peak longitudinal stress compared with control patients (A). There was no significant difference in peak circumferential stress between the dissected and control cohorts (B). Dot plots indicated individual measurements with horizontal bars serving as the median value.

properties may be a predisposing factor to the increased dissection risk observed in these specific high-risk populations. However, none of these studies used predissection images from patients known to dissect.

The landmark study by Rylski and colleagues ${ }^{24}$ investigated the pronounced changes in geometry of the thoracic aorta by the event of aortic dissection, finding an increase in diameter that is most pronounced in the ascending aorta. It underscored the critical importance of predissection imaging as the more reliable metric for dissection risk and served as a basis for this work. Although sparse, there has been previously published data on predissection aortic parameters and biomechanics of patients without BAV and without connective disorder who ultimately sustained TAAD. Krüger and colleagues ${ }^{25,26}$ measured ascending aortic length parameters from predissection CTAs in a comparable sized cohort of dissected and nondissected patients. They found predissected patients to have significantly elongated ascending aortas comparted with nondissected controls. Yamada and colleagues ${ }^{27}$ investigated aortic distensibility in aortic specimens obtained postdissection using tissue uniaxial testing. Interestingly, their histologic analysis of the tissue specimens showed decreased elastin content in the dissected cohort, but uniaxial testing suggested increased, rather than decreased, distensibility among patients who sustained dissection. No image-based predissection biomechanical assessments were available, and the average age of their cohort was 70 years, significantly greater than seen here. Such findings may further underscore the confounding biomechanical changes that occur in aortic dissection.

Using predissection clinically measured ascending aortic strain and CTA-reconstructed aortic geometry, we generated patient-specific stress/strain models that correlated increased areas of predissection predicted longitudinal stress with primary tear sites at the time of dissection. Finite element simulation and associated biomechanical analysis as a means to assess aortic dissection risk have been previously posited. ${ }^{14,28-33}$ However, these previous studies focused on the maximum circumferential stress or stretch as the limiting factor, and the dissection-risk metrics discussed in these studies were devoid of clinical data validation. For example, Beller and colleagues ${ }^{31}$ suggested that longitudinal stress, resulting from aortic root motion, was greater in areas of greatest risk of dissection. However, this study was performed not on patient-specific, but rather, generalized geometry of the thoracic aorta. In contrast, our multiparameter and patient-specific stress analysis reveals that only luminal pressure can produce significantly high longitudinal wall stress for dissection patients. We found distinctly that the location of the primary tear site corresponded to regions of predicted peak longitudinal wall stress for all the patients studied. Although there is heterogeneity both along the aorta and about its circumference, the experimental data available to us did not allow for the differentiation of material parameters within aortic layers. However, the elasticity measurements by transthoracic echocardiography along the long axis incorporate all the circumferential layers of the aorta and we would argue is more clinically relevant. Regional variation in the material properties would require a 3-dimensional measure of the tissue strains over the cardiac cycle, data not available in a retrospective study such as this. Although in vivo collection is possible, ${ }^{34}$ this would be unobtainable in a patientspecific manner during preoperative risk assessment.

Our results herein support the inclusion of aortic biomechanical parameters into a predictive model of aortic dissection risk. Our next goal is to develop a usable, patient-specific, multiparameter computational model that includes both cross-sectional imaging and dynamic distensibility indices to better adjudicate aortic dissection 
potential and to better define more appropriate criteria for surgical intervention.

\section{Limitations}

The number of patients for whom we had multiple predissection CTAs and echocardiograms among a consecutive series of TAADs was small $(n=7)$ relative to the total cohort mined $(n=351)$ and consequently may not be representative of the entire TAAD population. We attempted to control for confounding variables and only selected patients who had multiple predissection imaging studies to improve accuracy in wall biomechanics measurements and subsequent stress map generation. In addition, we did not compare patients with aneurysms who did experience dissection with those who did not. This comparison is the subject of an ongoing study by our group and will be an important component to developing a model that predicts aortic dissection potential.

The distensibility data collected in this study only provided a measure of the wall stiffness in the circumferential direction. Because of the retrospective nature of this study, we chose the location of measurement from previously published work for consistency. We chose not to use the location of maximum aortic diameters, as such locations are difficult to identify on transthoracic echocardiography. To that end however, we are currently working on a prospective distensibility study using intraoperative transesophageal echocardiography, which will allow for such measurements. For the computational simulations, we assumed that the stiffness in the longitudinal direction was similar to that in the circumferential direction, thus motivating our use of an isotropic material model. Our future work will include other methods of distensibility measurements.

\section{CONCLUSIONS}

Using a combination of echocardiographic assessment of ascending aortic wall distensibility and CTAreconstructed stress regional modeling, we generated patient-specific regional stress maps that revealed greater predissection longitudinal wall stress in patients who subsequently sustained TAAD. We show that longitudinal stress should be considered for patient stratification in addition to the usual diameter criterion. In addition, we would also support a greater use of aortic elasticity in the assessment of these patients. These findings support using a new, biomechanically based approach to predicting aortic dissection potential using multiple patient-specific imaging data points. A biomechanically based paradigm using patient-specific metrics will likely improve our ability to predict aortic dissection potential and thus better direct appropriate elective aortic intervention relative to the current guidelines that are based on maximal orthogonal aortic dimensions.

\section{Conflict of Interest Statement}

The University of Pittsburgh/UPMC receives industrial research support from Medtronic, Inc, and Boston Scientific, Inc, on behalf of Dr Thomas Gleason's role on national steering committees for work unrelated to this study. Dr Thomas Gleason also serves on a Medical Advisory Board for Abbott, Abbott Park, Ill, as well as Cytosorbants Corp, Monmouth Junction, NJ. All other authors have nothing to disclose with regard to commercial support.

The authors gratefully acknowledge Kristin Valchar, Melissa Enlow, and Julie Schreiber for assistance with institutional review board protocols and informed patient consent as well as image acquisition.

\section{References}

1. Nienaber CA, Clough RE, Sakalihasan N, Suzuki T, Gibbs R, Mussa F, et al. Aortic dissection. Nat Rev Dis Primers. 2016;2:16053.

2. Hirst AE Jr, Johns VJ Jr, Kime SW Jr. Dissecting aneurysm of the aorta: a review of 505 cases. Medicine. 1958;37:217-79.

3. Trimarchi S, Nienaber CA, Rampoldi V, Myrmel T, Suzuki T, Mehta RH, et al. Contemporary results of surgery in acute type A aortic dissection: the international registry of acute aortic dissection experience. J Thorac Cardiovasc Surg. 2005;129:112-22.

4. Erbel R, Aboyans V, Boileau C, Bossone E, Bartolomeo RD, Eggebrecht H, et al. 2014 ESC guidelines on the diagnosis and treatment of aortic diseases: document covering acute and chronic aortic diseases of the thoracic and abdominal aorta of the adult. The task force for the diagnosis and treatment of aortic diseases of the European Society of Cardiology (ESC). Eur Heart J. 2014;35:2873-926.

5. Parish LM, Gorman JH III, Kahn S, Plappert T, St. John-Sutton MG, Bavaria JE, et al. Aortic size in acute type A dissection: implications for preventive ascending aortic replacement. Eur J Cardiothorac Surg. 2009;35:941-6.

6. Pape LA, Tsai TT, Isselbacher EM, Oh JK, O'Gara PT, Evangelista A, et al. Aortic diameter $>$ or $=5.5 \mathrm{~cm}$ is not a good predictor of type A aortic dissection: observations from the international registry of acute aortic dissection (IRAD). Circulation. 2007;116:1120-7.

7. Baumgartner D, Baumgartner C, Matyas G, Steinmann B, Loffler-Ragg J, Schermer E, et al. Diagnostic power of aortic elastic properties in young patients with Marfan syndrome. J Thorac Cardiovasc Surg. 2005;129:730-9.

8. Nollen GJ, Groenink M, Tijssen JG, Van Der Wall EE, Mulder BJ. Aortic stiffness and diameter predict progressive aortic dilatation in patients with Marfan syndrome. Eur Heart J. 2004;25:1146-52.

9. Nistri S, Grande-Allen J, Noale M, Basso C, Siviero P, Maggi S, et al. Aortic elasticity and size in bicuspid aortic valve syndrome. Eur Heart J. 2008;29:472-9.

10. Pichamuthu JE, Phillippi JA, Cleary DA, Chew DW, Hempel J, Vorp DA, et al. Differential tensile strength and collagen composition in ascending aortic aneurysms by aortic valve phenotype. Ann Thorac Surg. 2013;96:2147-54.

11. Pham T, Martin C, Elefteriades J, Sun W. Biomechanical characterization of ascending aortic aneurysm with concomitant bicuspid aortic valve and bovine aortic arch. Acta Biomater. 2013:9:7927-36.

12. Pasta S, Rinaudo A, Luca A, Pilato M, Scardulla C, Gleason TG, et al. Difference in hemodynamic and wall stress of ascending thoracic aortic aneurysms with bicuspid and tricuspid aortic valve. J Biomech. 2013;46:1729-38.

13. Viscardi F, Vergara C, Antiga L, Merelli S, Veneziani A, Puppini G, et al. Comparative finite element model analysis of ascending aortic flow in bicuspid and tricuspid aortic valve. Artif Organs. 2010;34:1114-20.

14. Nathan DP, Xu C, Gorman JH III, Fairman RM, Bavaria JE, Gorman RC, et al. Pathogenesis of acute aortic dissection: a finite element stress analysis. Ann Thorac Surg. 2011;91:458-63.

15. Ikonomidis I, Lekakis J, Stamatelopoulos K, Markomihelakis N, Kaklamanis PG, Mavrikakis M. Aortic elastic properties and left ventricular diastolic function in patients with Adamantiades-Behcet's disease. J Am Coll Cardiol. 2004;43: 1075-81.

16. Jeremy RW, Huang H, Hwa J, McCarron H, Hughes CF, Richards JG. Relation between age, arterial distensibility, and aortic dilatation in the Marfan syndrome. Am J Cardiol. 1994;74:369-73. 
17. Raghavan ML, Vorp DA. Toward a biomechanical tool to evaluate rupture potential of abdominal aortic aneurysm: identification of a finite strain constitutive model and evaluation of its applicability. J Biomech. 2000;33: 475-82.

18. Holzapfel GA, Gasser TC, Ogden RW. A new constitutive framework for arterial wall mechanics and a comparative study of material models. J Elasticity Phys Sci Sol. 2000;61:1-48.

19. Vande Geest J, Bohra A, Sun W, Di Martino E, Sacks MS, Vorp DA. Development and 3D finite element implementation of a multiaxial constitutive relation for abdominal aortic aneurysms. Adv Bioeng. 2004;221-2.

20. Nistri S, Sorbo MD, Basso C, Thiene G. Bicuspid aortic valve: abnormal aortic elastic properties. J Heart Valve Dis. 2002;11:369-73; discussion 73-4.

21. Alireza M, Mohammad K, Shahnaz S. Aortic distensibility in bicuspid aortic valve patients with normal aortic diameter. Ther Adv Cardiovasc Dis. 2014;8: 128-32.

22. Vitarelli A, Conde Y, Cimino E, D’Angeli I, D’Orazio S, Stellato S, et al. Aortic wall mechanics in the Marfan syndrome assessed by transesophageal tissue Doppler echocardiography. Am J Cardiol. 2006;97:571-7.

23. Xuan Y, Wang Z, Liu R, Haraldsson H, Hope MD, Saloner DA, et al. Wall stress on ascending thoracic aortic aneurysms with bicuspid compared to tricuspid aortic valve. J Thorac Cardiovasc Surg. 2018;156:492-500.

24. Rylski B, Blanke P, Beyersdorf F, Desai ND, Milewski RK, Siepe M, et al. How does the ascending aorta geometry change when it dissects? J Am Coll Cardiol. 2014;63:1311-9.

25. Krüger T, Oikonomou A, Schibilsky D, Lescan M, Bregel K, Vöhringer L, et al. Aortic elongation and the risk for dissection: the Tübingen aortic pathoanatomy (TAIPAN) project. Eur J Cardiothorac Surg. 2017;51:1119-26.
26. Krüger T, Forkavets O, Veseli K, Lausberg H, Vohringer L, Schneider W, et al Ascending aortic elongation and the risk of dissection. Eur J Cardiothorac Surg. 2016;50:241-7.

27. Yamada H, Sakata N, Wada H, Tashiro T, Tayama E. Age-related distensibility and histology of the ascending aorta in elderly patients with acute aortic dissection. J Biomech. 2015;48:3267-73.

28. Fillinger MF, Raghavan ML, Marra SP, Cronenwett JL, Kennedy FE. In vivo analysis of mechanical wall stress and abdominal aortic aneurysm rupture risk. J Vasc Surg. 2002;36:589-97.

29. Pasta S, Phillippi JA, Tsamis A, D’Amore A, Raffa GM, Pilato M, et al. Constitutive modeling of ascending thoracic aortic aneurysms using microstructural parameters. Med Eng Phys. 2016;38:121-30.

30. Martin C, Sun W, Elefteriades J. Patient-specific finite element analysis of ascending aorta aneurysms. Am J Physiol Heart Circ Physiol. 2015;308:H1306-16.

31. Beller CJ, Labrosse MR, Thubrikar MJ, Robicsek F. Role of aortic root motion in the pathogenesis of aortic dissection. Circulation. 2004;109:763.

32. Martin C, Sun W, Pham T, Elefteriades J. Predictive biomechanical analysis of ascending aortic aneurysm rupture potential. Acta Biomater. 2013;9:9392-400.

33. Duprey A, Trabelsi O, Vola M, Favre JP, Avril S. Biaxial rupture properties of ascending thoracic aortic aneurysms. Acta Biomater. 2016;42:273-85.

34. Pasta S, Phillippi JA, Gleason TG, Vorp DA. Effect of aneurysm on the mechanical dissection properties of the human ascending thoracic aorta. J Thorac Cardiovasc Surg. 2012;143:460-7.

Key Words: aortic aneurysm, aortic dissection, aortic wall stress, aortic biomechanical properties 